\title{
Patents Analysis on Electric Vehicle Power Battery Technology in China
}

\author{
Jie Ming Liu", a ,Ju Cheng ${ }^{2, b^{*}}, \mathrm{Xi}$ Lin Yin ${ }^{3, \mathrm{c}}$ and Chen $\mathrm{Xu}^{4, \mathrm{~d}}$ \\ ${ }^{1}$ School of Arts and Law, Wuhan University of Technology, Wuhan, China \\ ${ }^{2}$ School of Arts and Law, Wuhan University of Technology, Wuhan, China \\ ${ }^{3}$ SAIC GM Wuling Automobile Co., Ltd, Liuzhou, China \\ ${ }^{4}$ School of Arts and Law, Wuhan University of Technology, Wuhan, China \\ a locus2003@163.com, b $^{*}$ songhae@163.com, ${ }^{c}$ Xilin.Yin@sgmw.com.cn, ${ }^{d}$ 601230139@qq.com
}

Keywords: Power battery; Battery management; Technology layout; Patent retrieval; Patent analysis.

\begin{abstract}
Power battery is the source of electric vehicle, which directly affects the performance and use cost. Through patent retrieval and patent analysis conclusion is palpable: China's power battery technology has been growing maturity gradually in recent ten years; framework of power battery patent layout has taken shape, namely, stress has been put on the fundamental battery technology and battery-based applications is getting some attention; automobile firms, battery manufacturers, foreign-funded new-energy companies and universities are main competitors in power battery field. To break bottle-neck technology it takes not only the nation to establish industrial planning but to select appropriate technical route and strengthen cooperation between the competitors.
\end{abstract}

\section{Research Survey}

Analysis of Power Battery Technology. Electric vehicle concerns mainly three types of key technologies, namely, power batteries, motor drive, electronic control. Currently valve regulated lead-acid battery, nickel hydrogen battery and lithium battery are more applied. However, the mentioned various types of cells monomer can not fully meet the requirements of electric vehicles in performance indices, namely, specific energy, specific power, charging technology, safety and cost. Besides, power batteries are generally put into application in group. The performance of battery pack is no better than original battery monomer. [1] The key factor of marketization and commercialization of electric vehicle comes to the development of power battery and battery application technology. [2]

The core technology of power battery comprises single battery technology, battery charging technology, batteries application technology, battery-safety technology, battery recycling technology.

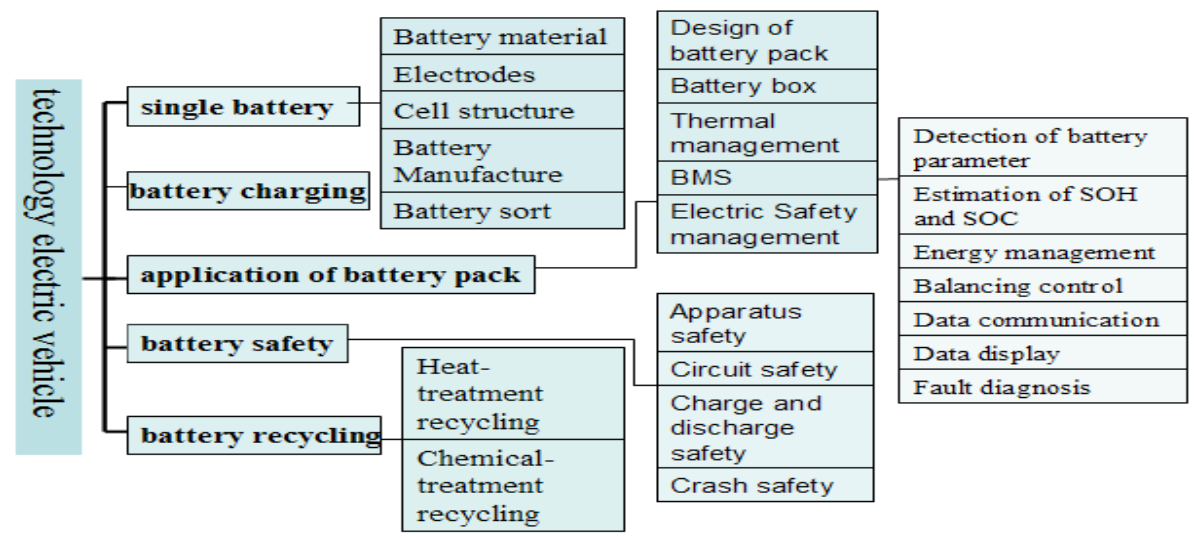

Figure. 1 Structure of electric battery technology

Among single battery technology branches battery materials and electrodes, manufacture of battery are more important. From the terms of battery application to electric vehicle, battery management system(BMS) and battery installation technology are key technology branches. Though detection of 
battery operation voltage, current, temperature Battery management system mainly estimate the state of charge( $\mathrm{SOC})$ and state of health( $\mathrm{SOH})$. On the base of state estimation BMS control maximum current and threshold voltage to achieve full protection of the cell.

Data Sources of Power Battery Patent Analysis. Patent data of Chinese electric vehicle battery comes from China's State Intellectual Property Office in February 2014. And retrieval range starts from earliest indexed literature in Chinese patent database to published patent literature until December 31, 2013.

In this paper, patent retrieval strategy suggested by Zhang Yi has been adopt, using key words and IPC Code to embody retrieve elements, combined with repeated tests by the features of database. [3] [4] IPC Code adopt in this paper include: H01M, H02J, H02H, B60K, B60R, G01R. [5]After data screening, 3299 effective patents were obtained in the field of China's power battery.

\section{Power Battery Patent Intelligence Analysis}

\section{Analysis of Patent Application Trend.}

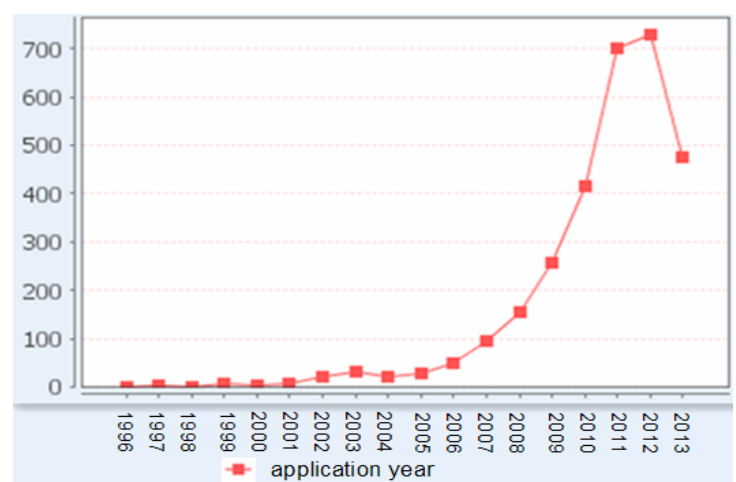

Figure. 2 China's power battery patent application annual trend

From the perspective of annual application quantity, China's research about power battery technology has experienced a radical increase stage from 2007 to 2012 followed by slow-growth between 2002 and 2006. It is not hard to find China's power battery technology has developed fast in recent years, and is in the transition from growth to maturity now. Moreover, there is still much room and value to continue researching the patent. [6]

With rapid development of automobile industry and needs for developing market, domestic automobile enterprises have been taking part in the development and manufacture of electric vehicle.

Analysis of Main Techniques. Firstly, overall condition of technology distributed by IPC Code:

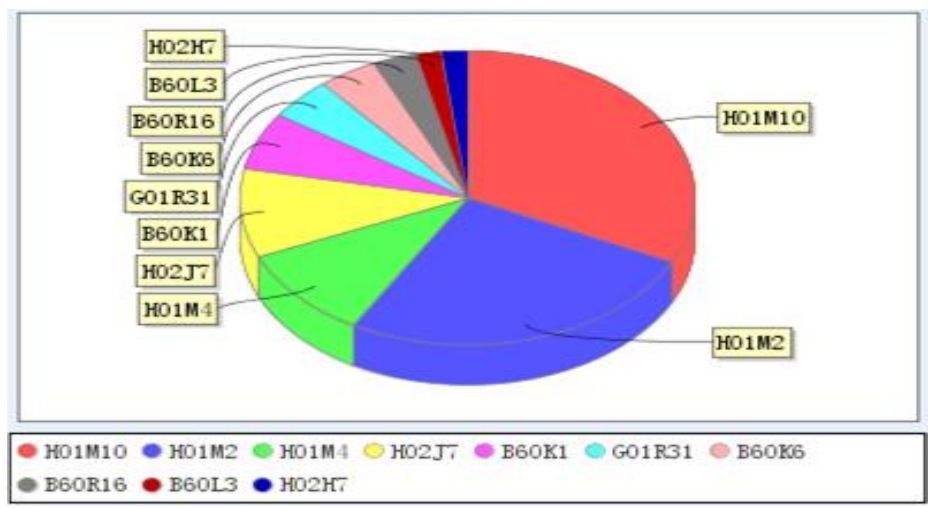

Figure. 3 Main technology branches of China's power battery patent in IPC Code

Secondary cells and their manufacture (H01M10), constructional details or processes of manufacture of the non-active parts (H01M2), electrodes (H01M4) which are to improve single battery dynamic performance are most significant technology branches. In addition, circuit arrangements for charging or depolarising batteries (H02J7) and battery management (G01R31) as technical difficulties are also the powerful motivator. Arrangement or mounting of electrical 
propulsion units (B60K1, B60K6) and electric or fluid circuits specially adapted for vehicles (B60R16) focus on the application of batteries in automobile, which belongs to the field of battery pack mechanical integration. Other techniques such as electric devices for safety purpose(B60L3), emergency protective circuit arrangements $(\mathrm{H} 02 \mathrm{H} 7)$ are to improve the safety performance of application of battery in auto as complementary research. [7]

Secondly, analysis of main technology branches application trend as follow:

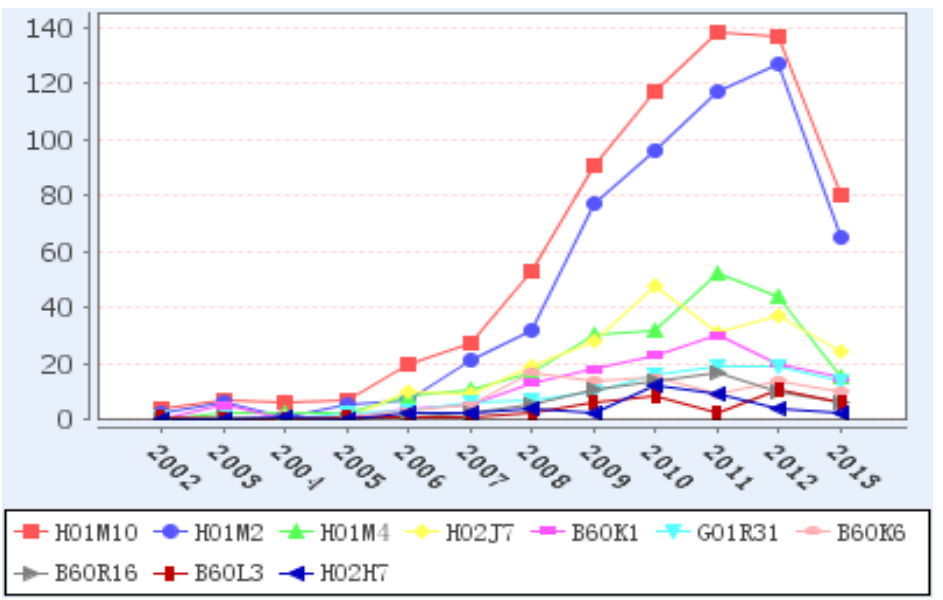

Figure. 4 Main technology branches of China's power battery patent annual application trend

Similar to the overall power battery patent application annual trend, three cores of technology branches H01M10, H01M2, H01M4 entered a rapid development from 2006 after small growth. In addition, H02J7, B60K1 and G01R31 started from 2008, lately then foregoing branches and showed a rather gentle tendency. With the demonstration promotion, the issues of battery application on vehicle have become prominent. The applicants pay attention both to the improvement of power battery technology but also the reasonable and effective control and integrated application. This development trend is beneficial for avoid passive situation contained by foreign peripheral patents.

Analysis of Main Applicant. Firstly, composite analysis of main patent applicants:

Table 1 Composite comparison and analysis of main applicants research capacity in power battery

\begin{tabular}{|c|c|c|c|c|c|}
\hline \multirow{2}{*}{ applicant } & \multirow{2}{*}{ quantity } & percent & \multicolumn{3}{|c|}{$\begin{array}{c}\text { comparison of applicant } \\
\text { research capacity }\end{array}$} \\
\cline { 5 - 6 } & & & $\begin{array}{c}\text { number } \\
\text { active } \\
\text { period }\end{array}$ & $\begin{array}{c}\text { nef } \\
\text { of } \\
\text { inventor }\end{array}$ & $\begin{array}{c}\text { patent } \\
\text { age }\end{array}$ \\
\hline BYD Co Ltd. & 96 & $12.47 \%$ & 11 & 141 & 4.86 \\
\hline Tianjin Lishen Battery Joint-Stock Co Ltd. & 90 & $11.69 \%$ & 9 & 87 & 4.4 \\
\hline Chongqing Changan Automobile Co Ltd. & 82 & $10.65 \%$ & 8 & 152 & 3.44 \\
\hline Chery Automobile Co Ltd. & 80 & $10.39 \%$ & 7 & 100 & 3.21 \\
\hline Geely Holding Group & 63 & $8.18 \%$ & 6 & 78 & 2.6 \\
\hline Zhejiang Geely Automobile Research & & & & & \\
\hline Institute & 55 & $7.14 \%$ & 5 & 74 & 2.45 \\
\hline Changan Amperex Automobile Co Ltd. & 52 & $6.75 \%$ & 4 & 96 & 2.71 \\
\hline Dongguan Amperex Technology Limited & 47 & $6.10 \%$ & 5 & 49 & 2.81 \\
\hline Beiqi Foton Motor Co Ltd. & 40 & $5.19 \%$ & 6 & 77 & 3.18 \\
\hline Lishen Miles Power Battery System Limited & 37 & $4.81 \%$ & 2 & 28 & 2.43 \\
\hline Wanxiang Electric Vehicle Co Ltd. & 33 & $4.29 \%$ & 8 & 62 & 3.85 \\
\hline Ningde Amperex Technology Limited & 33 & $4.29 \%$ & 4 & 39 & 2.21 \\
\hline Tsinghua University & 32 & $4.16 \%$ & 8 & 58 & 3.75 \\
\hline Beijing Institute of Technology & 30 & $3.90 \%$ & 9 & 33 & 4.97 \\
\hline
\end{tabular}


So far Geely Group is the primal competitor with 15.32 percent, followed by other independent automobile enterprises. BYD Co Ltd. and Tianjin Lishen Battery Joint-Stock Co. which specialized in accumulator have got great achievements in electrically-propelled vehicle. Dongguan Amperex Technology Limited(ATL) and Ningde Amperex Technology Limited all are solely owned by Japanese. By contrast, domestic scientific institution is not so prominent, expect for Tsinghua University and Beijing Institute of Technology. And it's worth noting that Japan as the leading power in hybrid electric vehicle has began patent distribution in China with amount of patents.

Secondly, analysis of main competitor application trend:

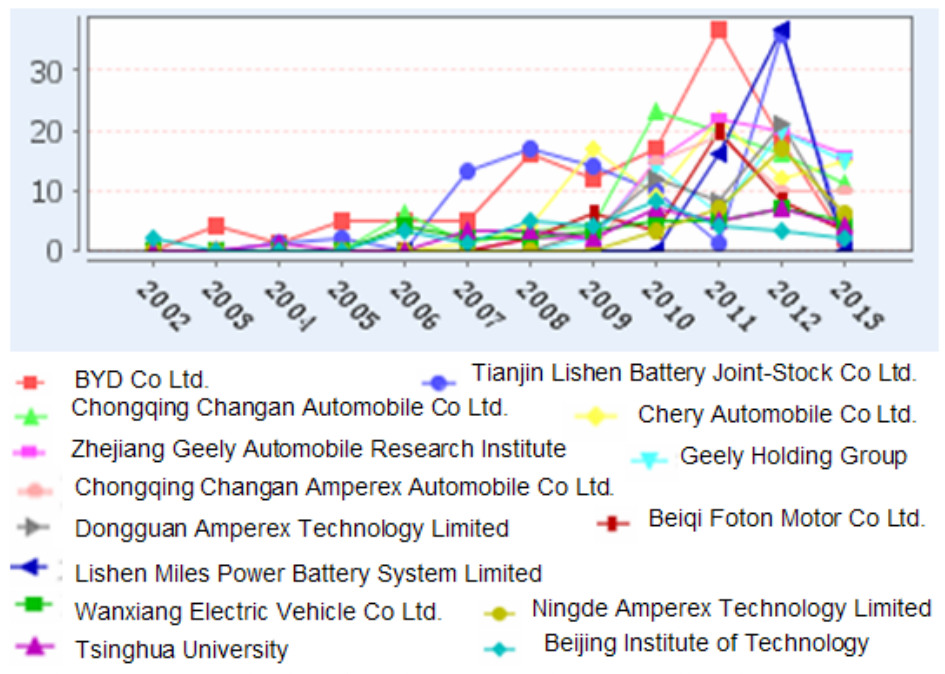

Figure. 5 Analysis of main competitors application trend

Nearly all applicants got a late start. Among them Tianjin Lishen is the earliest one which shows unstable growth carve from 2006. BYD Co Ltd. has experienced steady increase to rapid growth. With accession of Geely Group, Chang'an Motors, Chery Automobile Co. into the field, applications are quite lively from 2010. Based on relatively long-term researches on power battery automobile manufacturers have more patents, forming comparatively technical advantage. Athough late in the field Amperex Technology Limited has kept fast and stable increase. And Tsinghua University and Beijing Institute of Technology are indispensable forces because of lots of accumulated theory research.

Thirdly, analysis of technology layout among main competitors:

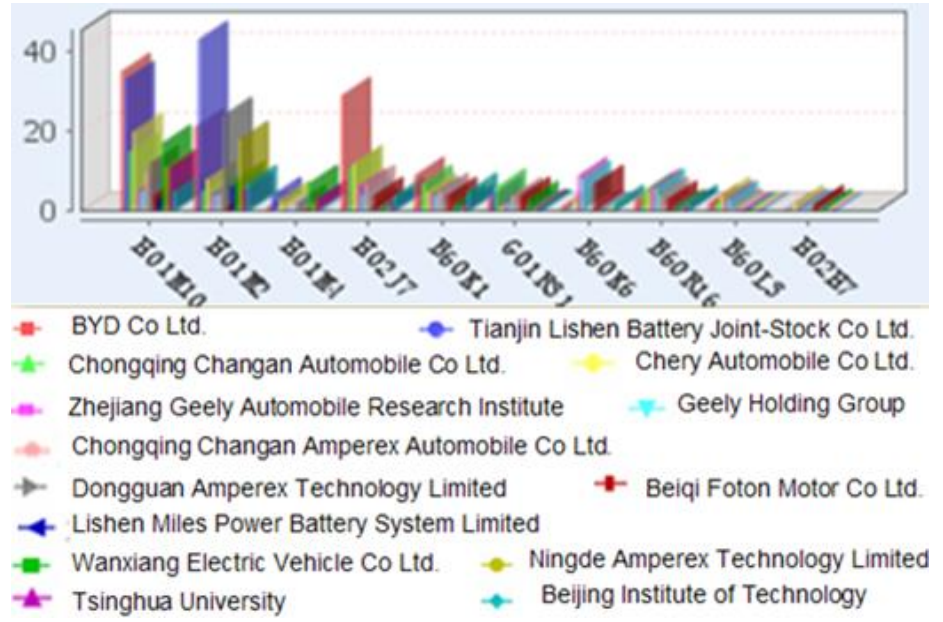

Figure. 6 Technology branches in IPC among main competitors

Data shows that H01M2, H01M10 and H02J7 are hot technologies for almost applicants. However, due to different industry backgrounds, the coverage of technology is limited for each applicant with more or less blank spots. And apparent differences in technology branches exist: Tianjin Lishen has a lead in H01M2, H01M10, and BYD Co Ltd. owns more patents in H02J7 and H01M10. 


\section{Conclusion and Suggestion}

Power Battery Technology Have Been Developing Steadily. In terms of increasing application from 2006, China has mastered part of core technologies and is characterized with strong competitiveness in power battery. The achievement indicates great innovation capability and provides technical support for the industry development.

But to worldwide extent, there is a gap between China and the advanced countries, especially Japan where most productive institutions gather. [8]According to statistics, global high-yield organizations of electric vehicle patent technology mainly concentrated in Japan, American, South Korea.

Therefore, it's necessary for China to get involved in the ranks of development of power battery more. To break through foreign patent technology siege and fight for initiative demands more inputs from following aspects:

Clear long-term electric vehicle industrial planning which fits specific national condition should be published by the state, combining with corresponding technical standards and patent strategy as technical support to gain international market competitive advantage.

Standardizing market competition, enriching industrialization policies and improve customer service also weigh much.

Framework of Patent Layout Has Taken Shape. Fundamental battery technology is priority and focus area of China's current direction and concern, For instance, secondary cells and manufacture, electrodes. However, Faced with the hardship to break bottleneck, China has began to turned attention to battery-based applications, namely, battery management system, arrangement of electrical propulsion units, electric or fluid circuits specially adapted for vehicles. [9]

It's advisable to diffuse focus from fundamental battery field to non-core application technology for temporary circumvention. Smooth auto operation needs not only high-performance battery but also more and more complex accurate parameter of vehicle control. This strategy of periphery occupation is to effectively prevent possible inopportune situation of being held back by peripheral patents.

Looked from overall performance, electric vehicle is the collection of high-tech including electronic technology, new materials. And in terms of market demands and given full play to China's advantages in electronic control, following peripheral areas are worth of attention: test and evaluation of battery safety performance; intelligent battery management system. [10]

There Is no Absolute Superiority among Competitors and Necessity to Collaborate. Independent automobile firms, battery manufacturers and foreign new energy company are main power in power battery research. There isn't yet competitor who can hold overwhelming superiority. Confronted with keen global competition uniting advantages of each side is essential.

It's necessary to strengthen alliance between different types of competitors. Based on the application and production capacity of auto producer and combined with research basis and teams of scientific institution, industry-university-research alliance will make full use of capital and market to accelerate productization and industrialize hi-tech.

Building interior union preponderance between similar competitors is also important. So far led by Association of Automobile Manufacturers, the "electric vehicle industry alliance" has set up. But it's supposed to push the introduction of standards in electric vehicle performance, manufacture and safety for promotion.

To reinforce coordination with foreign advanced institutions makes much sense as well. Foreign companies represented by ATL utilize mounts of patents to build their technology network. China's applicant ought to actively seek opportunity to cooperating with prominent foreign institution and fuse their technical feature.

Technology Path of Power Battery Field in China.Through patent data analysis there comes some summarized proposal of China's power batteries technology development with the technology path (Fig.7) to interpret, which is wished to provide beneficial references for researchers. 


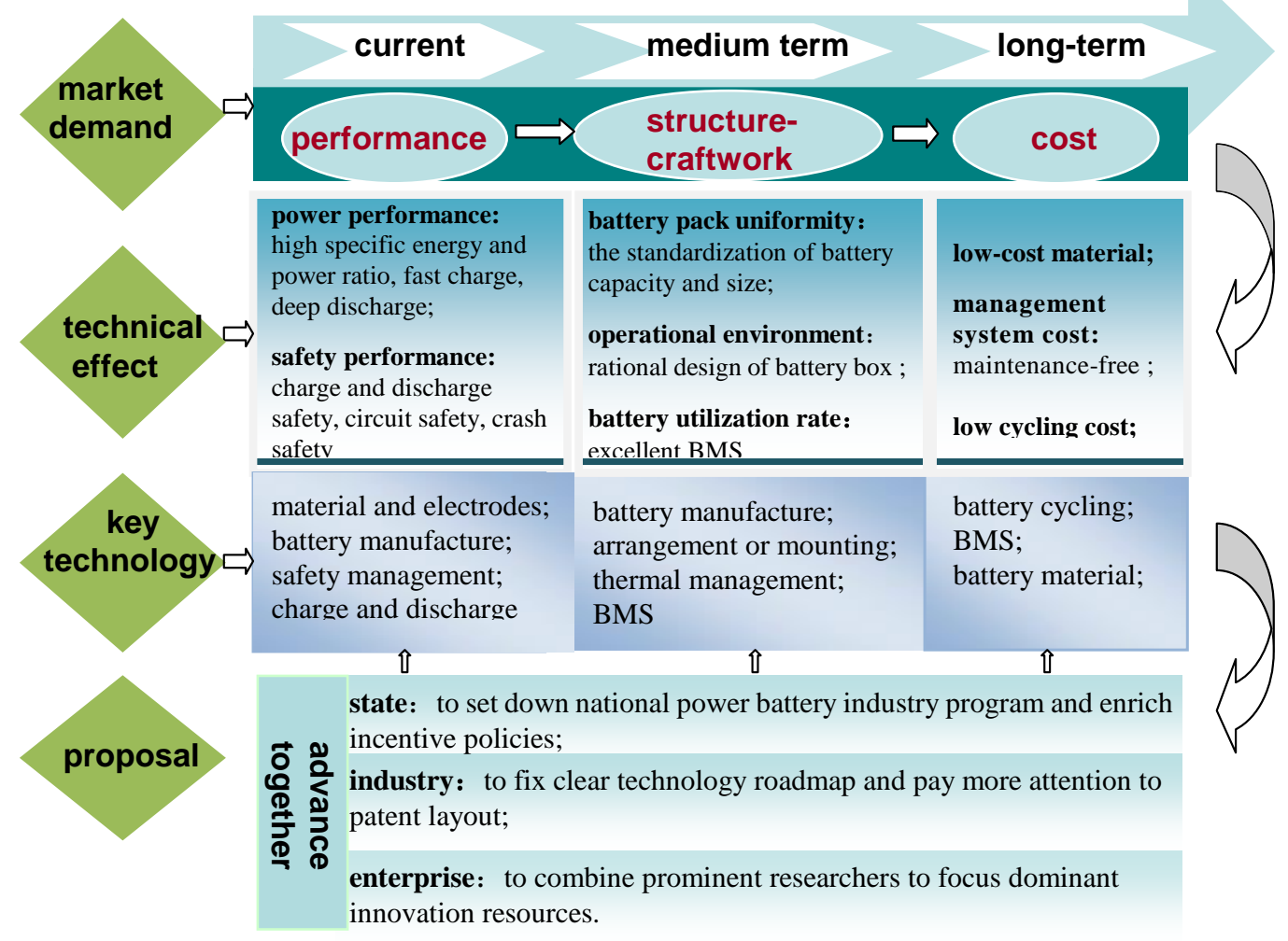

Figure. 7 Technology path of power battery field in China

Given consideration to increasingly mature electric vehicle technology, consumption demand for electric cars will gradually translate from high performance to fine craft and structure, low cost. And emphasis of core technology research of power battery will change accordingly. Combined with stage of China's power battery development, the following government-industry-enterprise aspects should be pushed on simultaneously while promoting power battery technology: deciding and adjusting the industry program from strategic height and macro level; paying attention to the patent layout of advanced countries and fixing clear technology roadmap combining with own advantage; conducting innovation subject through various policy and focusing dominant resources to key technology.

\section{References}

[1] Z.P. Wang and X.F. Meng: Advanced Materials Industry,Vol.8(2007), p.37-38 (In Chinese)

[2] J. Tollefson: Nature, Vol. 456 (2008), p.436-440.

[3] Y. Zhang, x.f. Wang, Y. Guo and D.H. Zhu: Studies in Science of Science, (2008) No.9, p.1-7. (In Chinese)

[4] S. Qi: Journal of Information, Vol. 28 (2009) No.8, p. 15-19. (In Chinese)

[5] D. Hunt, L.Nguyen and M. Rodgers: Patent Searching: Tools \& Techniques(John Wiley \& Sons, America 2007).

[6] A. Abbas, L.M. Zhang, S. Khan: World Patent Information, Vol.37 (2014), No.6, p.3-13.

[7] J.R. Nan, F.C. Sun and J.Q. Wang.: Journal of Tsinghua University(science and technology), Vol. 47 (2007) No.2, p. 89-94. (In Chinese) 
[8] C.J. Luan: Technology and Innovation Management, Vol. 32 (2011) No.2, p. 115-116. (In Chinese)

[9] C.T. Lin, J.P.Wang and Q.S.Chen: Battery Bimonthly, Vol. 34 (2004) No.5, p. 136-144. (In Chinese)

[10] B.X. Cui, X. Sui, J.H. Zhao, L. Chang and L.Li: Electronics Intellectual Property, (2010) No.6, p. 62-66. (In Chinese) 